\title{
Seismic Response of Sri Lanka using DSHA Technique
}

\section{D.R. Weerasinghe, H.N. Seneviratne, L.C. Kurukulasuriya and K.K. Wijesundara}

Abstract: Deterministic seismic hazard assessment developed in 1960s is the oldest method of analysis of seismic ground response. This paper describes the application of seismic hazard assessment to obtain the Peak Ground Acceleration at major cities in Sri Lanka due to an oceanic earthquake. Two earthquakes, occurred in 2011 and 2012 in the above region, were chosen for the validation of suitable attenuation relationships for the region. The comparison shows that, out of the two attenuation relationships investigated, Gitterman et al. (1993) relationship gives the best prediction.

Keywords: Controlling Earthquake, Peak Ground Acceleration, Attenuation Relationships

\section{Introduction}

Earthquakes are created by the energy release due to relative movement either between the plates (interplate) or at the weak planes on the plate (intraplate). The terminology used in describing the position of an earthquake is illustrated in Figure 1. The central point of the area of rupture is called the focus of the earthquake. The point on the ground surface directly above the focus, either in the sea or in land, is referred to as the epicenter of the earthquake. The epicentral distance is the horizontal distance from the epicenter to the point of interest.

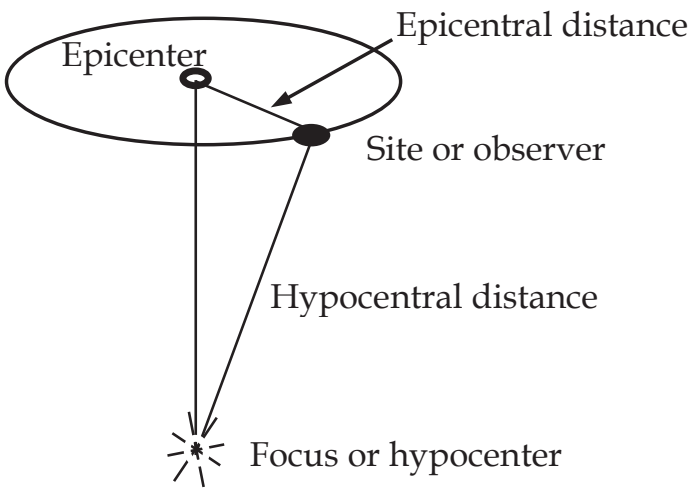

Figure 1 - Terminology used in Earthquakes

The energy released by an earthquake creates elastic body waves at the focus which propagates uniformly radially outwards along the medium (rock) subjected to dispersion and attenuation with travel. These seismic waves are called P (Compression) or S (Shear) waves depending on their motion characteristics. $\mathrm{P}$ waves travel faster than $\mathrm{S}$ waves and therefore, are the first to arrive at the point of interest. When the P or S waves encounter the ground surface they transform into surface waves called Rayleigh waves and Love waves. These surface waves disperse slowly but decay faster than $\mathrm{P}$ and $\mathrm{S}$ waves. Rayleigh waves and Love waves travel together and they are the cause of the most damage considering all waves, within a radius of about $100 \mathrm{~km}$ from the epicenter.

The seismic scenario around Sri Lanka is described in detail by Seneviratne et al. (2019) [8]. Considering past earthquake records in the west coast region of Sri Lanka, the epicentral distance to the coastline has been large (over $100 \mathrm{~km}$ usually) in most of the ocean earthquakes. Here the energy dissipation and dispersion due to an oceanic earthquake can be modelled as two separate problems, namely;

(i). From epicenter to continental shelf

(ii).From continental shelf to the point of interest on the land.

In the case of earthquakes originating within Sri Lanka, only the latter problem has to be considered.

Eng. D.R. Weerasinghe, BSc. Eng.(Hons) (Peradeniya), PhD Candidate, Department of Civil Engineering, Monash University, Australia.

Eng. (Prof.) H.N. Seneviratne, C. Eng., FIE(SL), BSC Eng. (Ceylon), PhD (Cantab), Senior Professor, Department of Civil Engineering, University of Peradeniya.

Email:nimalseneviratne1@gmail.com

(i) http://orcid.org/0000-0001-5352-2652

Eng. (Dr.) L.C. Kurukulasuriya, C. Eng., MIE(SL), BSc Eng. (Moratuwa), MSc Eng., PhD (Saitama), Senior Lecturer, Department of Civil Engineering, University of Peradeniya.

Email:chank@pdn.ac.lk

(ii) http://orcid.org/0000-0003-1448-5734

Eng. (Dr.) K.K. Wijesundara, AMIE(SL), BSc Eng.

(Peradeniya), MSc Eng (Pavia), PhD (Pavia), Senior Lecturer, Department of Civil Engineering, University of Peradeniya.

Email:kushanw@pdn.ac.lk

(10) http://orcid.org/0000-0002-4174-8707 
Deterministic Seismic Hazard Assessment (DSHA) and Probabilistic Seismic Hazard Assessment (PSHA) are the well-known techniques used to determine the ground motion at a point of interest due to an earthquake [4]. This paper describes a study performed to determine seismic hazard assessment of Sri Lanka using the DSHA technique. The impact of oceanic earthquakes originating in proximity to Sri Lanka in the failed Mannar rift zone and Comorin ridge region is considered in the analysis. The effect of attenuation of seismic waves due to soil overburden was not considered.

\section{Deterministic Seismic Hazard Assessment (DSHA) Technique}

Deterministic Seismic Hazard Analysis (DSHA) was one of the popular approaches in early years of geotechnical earthquake engineering. In this approach, a seismic scenario is developed on the basis of ground motion hazard evaluation. The scenario consists of an occurrence of an earthquake of a specified magnitude at a specific location. DSHA approach can be elaborated as explained by Reiter (1990) [7] as follows.

Firstly, a controlling earthquake is selected by considering the level of shaking. The earthquake, which has the strongest level of shaking, is chosen as the controlling earthquake. Generally this is expressed in terms of some ground motion parameters. The controlling earthquake is characterised in terms of its size and distance from the point of interest.

At the beginning of an analysis, all earthquake sources which are capable of producing a significant ground motion at the point of interest are considered and these sources are characterized depending on geometry and earthquake potential. Then the distance from each source to the point of interest is determined. When selecting the distance, the usual practice is to take the shortest epicentral distance between the source and the point of interest.

The threat to the point of interest is clearly defined, usually in relation to the ground motion occurred due to the controlling earthquake. Characteristics such as Peak Ground Acceleration (PGA), Peak Ground Velocity (PGV), Peak Ground Displacement (PGD) and Spectral Acceleration (SA) which indicate the threat to the site are obtained by one or more attenuation relationships.

Attenuation relationships are those given in the literature based on models developed and calibrated using past earthquake and attenuation data taken from earthquakes in different parts of the world. Examples of such relationships are those developed for strong motion data from Israel [3] and those developed using crustal earthquake data from Taiwan [5]. When selecting suitable attenuation relationships, it is important to consider relations which are developed using data from similar seismic scenarios. Wherever possible, the selected relationships should be verified using actual data from the site.

\section{Seismic Scenario around Sri Lanka}

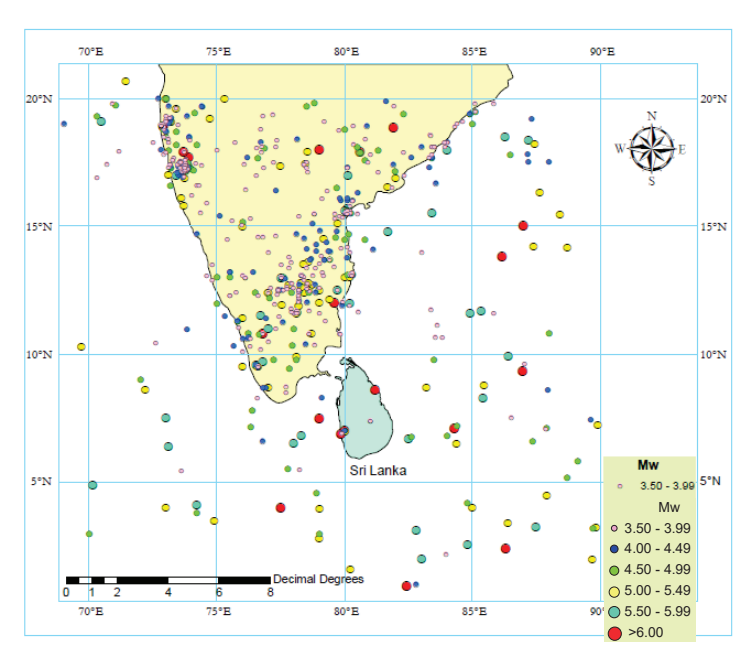

Figure 2 - Earthquake catalogue since 1900

The seismic scenario surrounding Sri Lanka with reference to earthquakes originating in the sea from NW to SW as described in Seneviratne et al. (2019) [8] has been used in the present analyses. This scenario, shown in Figure 2, comprises the seismic activity associated with Comorin ridge and failed Mannar rift zone, including records of 30 earthquakes of magnitude 3.0 - 6.5 covering the period from 1900 to 2014. The seismic activity inside Sri Lanka and in the other oceanic regions around Sri Lanka is unlikely to present a significant hazard as described in Seneviratne et al. (2019) [8]. Only other area of concern is the northern part of the country which may be influenced by tectonic activities in the South Indian region. However, they are not considered in this paper. 


\section{Attenuation Relationships}

Several attenuation relationships from the literature had been studied to be used in the simulation, namely (a) Abrahamson and Silva (1997) [1], (b) Raghukanth and Iyengar (2007) [6], (c) Campbell and Bozorgnia (2008) [2], (d) Gitterman et al. (1993) [3] and (e) Kun-Sung and Yi-Ben (2005) [5]. They cover a wide spectrum of seismic scenarios. For example, (a) covers the earthquakes recorded all over the world including both inter plate and intraplate earthquakes; (b) includes earthquake data from Indian sub-continent; and (c) includes data from Western United States which has moderate seismicity. The preliminary DSHA analyses performed showed that two attenuation relationships given below give the optimum performance in predicting the median ground motion response within Sri Lanka due to the seismic scenario stated in Section 3. These attenuation relationships are:

i. Gitterman et al. (1993): developed for strong motion data from Israel

$\log (\boldsymbol{P G} \boldsymbol{A} / \boldsymbol{g})=-1.02+0.249 \boldsymbol{M}-\log \boldsymbol{R}-0.00255 \boldsymbol{R}$

ii.Kun-Sung and Yi-Ben (2005): developed using crustal earthquake data from Taiwan $\ln (\boldsymbol{P G} \boldsymbol{A})=-0.852 \ln (\boldsymbol{X}+1.24)-0.0071 \boldsymbol{X}+1.027 \boldsymbol{M}+1.062$

In the above equations: PGA, the Peak Ground Acceleration given in $\mathrm{cm} / \mathrm{s}^{2}, g$, the gravitational acceleration, $M$, the moment magnitude of the earthquake, and $R$ and $X$ respectively the epicentral and hypocentral distances in $\mathrm{km}$ to the point at which PGA was calculated.

\section{Calibration Data}

As described in Seneviratne et al. (2019) [8], there was a seismograph in operation at Colombo Observatory during the period from 1908 to 1992 . Unfortunately however, there are no ground response records readily available from this instrument. The seismic network established by the Geological Survey and Mines Bureau (GSMB) comprises the seismic monitoring stations at Pallekele (PALK), Mahakandarawa (MALK) and Hakmana (HALK) established in 2000, 2010 and 2010 respectively, as shown in Figure 3. However, these stations are at a considerable distance away from the Comorin ridge and the Failed Mannar rift zone along which intense seismic activity had been observed in the past. HALK, MALK and PALK record the bedrock acceleration-time data of arrived seismic waves at the monitoring stations.

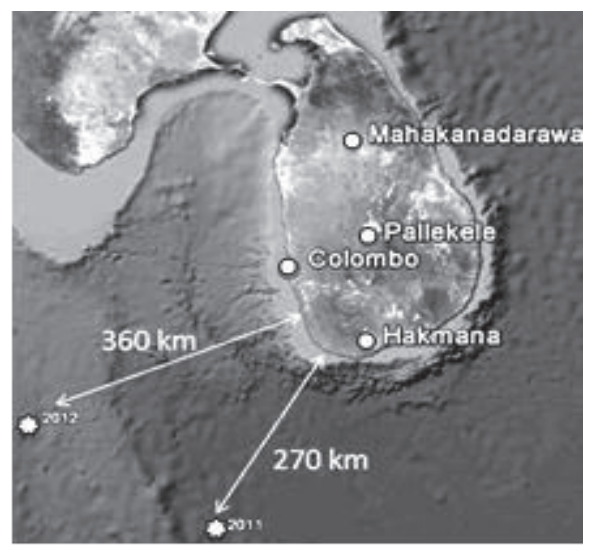

Figure 3 - Seismic monitoring stations in Sri Lanka

The most complete dataset of significant seismic events which took place after the installation of GSMB stations was used in calibrating the attenuating relationships described above. The seismic events which occurred since the installation of GSMB stations are moderate in magnitude $(\mathrm{M}<5)$. Also in some of the events, records are not available at all three stations. The two seismic events in 2011 and 2012, the only events for which complete records are available at GSMB up to July 2012 [9], are used for calibration of the attenuation relationships. The epicentral distances of these events are over $400 \mathrm{~km}$ and with depth of the focus around $10 \mathrm{~km}$, the hypocentral distance can be taken as equal to the epicentral distance without any significant loss of accuracy.

Table 1 - Past earthquake records from GSMB stations up to 2012 - complete records only [9]

\begin{tabular}{|c|c|c|c|c|c|}
\hline Year & Mag. & $\begin{array}{c}\text { GSMB } \\
\text { Station }\end{array}$ & $\begin{array}{c}\text { Distance } \\
\text { from } \\
\text { Epicenter } \\
\mathbf{( k m )}\end{array}$ & $\begin{array}{c}\text { Dep } \\
\mathbf{t h} \\
\mathbf{( k m} \\
\mathbf{~}\end{array}$ & PGA/(g) \\
\hline 2012 & 4.2 & HALK & 420 & 2 & 0.000029 \\
\hline & & PALK & 472 & 10 & 0.000046 \\
\hline & & MALK & 532 & 2 & 0.000037 \\
\hline 2011 & 4.7 & HALK & 304 & 2 & 0.000153 \\
\hline & & PALK & 418 & 10 & 0.000252 \\
\hline & & MALK & 526 & 2 & 0.000089 \\
\hline
\end{tabular}

\section{Comparison of Attenuation Relationships}

The data presented in the previous section are compared with those predicted by the two attenuation relationships described above. 


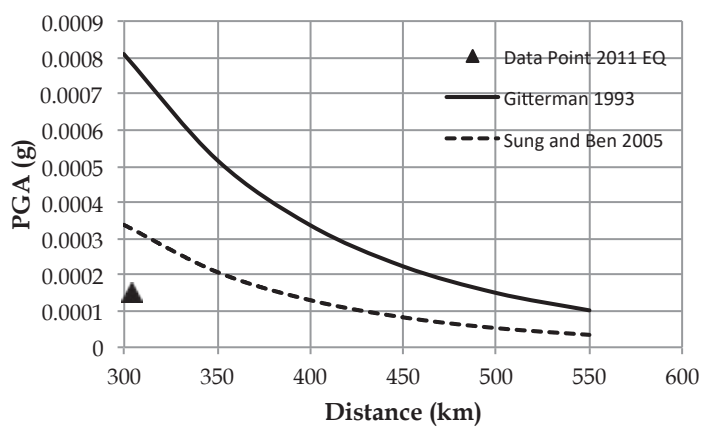

Figure 4 - Comparison of the attenuation relationships with recorded data from 2011 earthquake

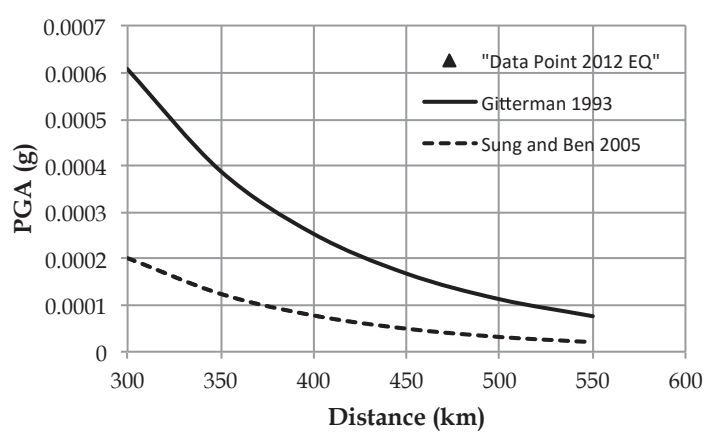

Figure 5 - Comparison of the attenuation relationships with recorded data from 2012 earthquake

It is clear from Figures 4 and 5 that the better estimated values are given by Kun-Sung and Yi-Ben (2005) [5] relationship for the 2012 earthquake and by Gitterman et al. (1993) [3] for the 2011 earthquake. Gitterman et al. (1993) [3] relationship gives a slightly higher estimate of the real behaviour except the data point at HALK where the real behaviour is significantly over-predicted. This may be due to the effect of differences in ground elevation profile on the wave attenuation along different directions from the epicenter. Out of the above two relationships, Gitterman et al. (1993) [3] relationship is chosen for the detailed study.

\section{Ground Motion Analyses - 2011 and 2012 Earthquakes}

The monitored ground time acceleration records of 2011 and 2012 earthquakes are processed to obtain Fourier spectra of ground acceleration records. This was performed for both NS and EW components of the seismic wave. Figure 6 shows the Fourier spectra of NS and EW components of time histories of ground acceleration recorded at Hakmana during 2011 and 2012 earthquakes. Similar spectra were obtained for all three stations in both NS and EW components of 2011 and 2012 events.

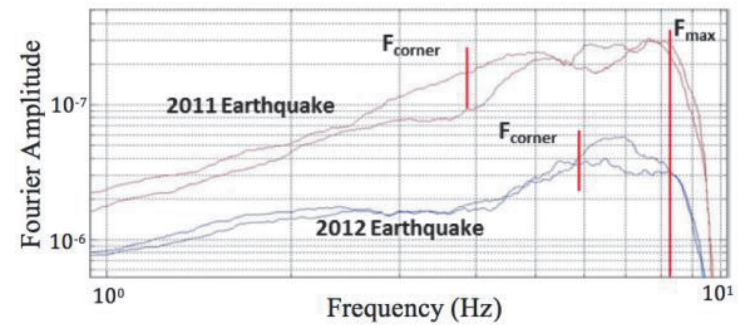

Figure 6 - Fourier spectra of recorded earthquake time histories in 2011 and 2012

It should be noted here that the sampling frequency at Hakmana and Mahakanadarawa is $20 \mathrm{~Hz}$ in contrast to $40 \mathrm{~Hz}$ at Pallekele. This makes the higher frequency content at Hakmana and Mahakanadarawa less accurate due to lower sampling rate.

\section{DSHA Analysis of Seismic Scenario in and around Sri Lanka}

Considering the seismic scenario in and around Sri Lanka as discussed in Seneviratne et al. (2019) [8] , two controlling earthquakes P and Q have been chosen for the DSHA analysis. Earthquake $\mathrm{P}$ is assumed to have a magnitude of 6.9 at an epicentral distance of $90 \mathrm{~km}$ from the western coastline. The magnitude of the earthquake is selected considering the potential energy release which is possible under intraplate tectonic activity as stated by seismologists [8]. The epicenter is placed along the Failed Mannar rift zone and Comorin ridge, the potential source of tectonic activity in the hazard zone.

Earthquake $\mathrm{Q}$ is placed $15 \mathrm{~km}$ away from the west coastline (epicenter) with a magnitude 6 on Richter scale. This is to investigate the influence of an earthquake of magnitude lower than critical, but occurring at a distance closer than critical.

Table 2 shows the PGA values at selected cities in Sri Lanka as predicted by Gitterman et al. (1993) [3] relationship for the selected seismic scenarios above. It should be noted that the PGA values proposed are for the bedrock response only. Usually, this is not a problem as the surface response at a given site can be easily evaluated using site investigation data such as SPT using wave propagation software such as Shake. This also applies to other possible phenomenon like liquefaction. The site specific information/effects are too complex to be considered at the present level of study. 
Table 2 - PGA values at selected cities in Sri Lanka

\begin{tabular}{|l|c|c|}
\hline \multirow{2}{*}{ City } & \multicolumn{2}{|c|}{ PGA (g) } \\
\cline { 2 - 3 } & M=6 at 15 $\mathbf{~ k m ~}$ & M=6.9 at 90 $\mathbf{~ m ~}$ \\
\hline Ampara & 0.004 & 0.006 \\
\hline Anuradhapura & 0.007 & 0.009 \\
\hline Badulla & 0.01 & 0.013 \\
\hline Batticaloa & 0.004 & 0.005 \\
\hline Colombo & 0.132 & 0.067 \\
\hline Dambulla & 0.009 & 0.012 \\
\hline Gampaha & 0.108 & 0.062 \\
\hline Galle & 0.016 & 0.019 \\
\hline Hambantota & 0.007 & 0.009 \\
\hline Horana & 0.08 & 0.054 \\
\hline Jaffna & 0.002 & 0.002 \\
\hline Kalutara & 0.061 & 0.047 \\
\hline Kandy & 0.018 & 0.021 \\
\hline Kurunegala & 0.023 & 0.025 \\
\hline Mannar & 0.003 & 0.005 \\
\hline Matara & 0.011 & 0.013 \\
\hline Negombo & 0.083 & 0.055 \\
\hline Nuwara Eliya & 0.016 & 0.019 \\
\hline Polonnaruwa & 0.007 & 0.009 \\
\hline Puttalam & 0.012 & 0.015 \\
\hline Rathnapura & 0.034 & 0.033 \\
\hline Trincomalee & 0.003 & 0.004 \\
\hline Vavuniya & 0.004 & 0.006 \\
\hline
\end{tabular}

\section{Conclusions}

When considering the past seismic activities around Sri Lanka, cities in the western province like Colombo, Negombo, Gampaha etc., which consist of highly populated and commercialized cities, can be exposed to PGA values of more than $0.1 \mathrm{~g}$. The study produced a PGA of $0.13 \mathrm{~g}$ for Colombo, which may cause moderate damages to structures, but for the non-engineered structures which are not designed for seismic effects, the damage can be severe.

\section{References}

1. Abrahamson, N. A. and Silva, W. J. (1997). "Empirical Response Spectral Attenuation Relations for Shallow Crustal Earthquakes", Seismological Research Letter, Vol. 68, No. 1, 94127.

2. Campbell, K. W. and Bozorgnia Y. (2008). “NGA ground Motion Model for the Geometric Mean Horizontal Component of PGA, PGV, PGD and 5\% Damped Linear Elastic Response Spectra for Periods Ranging from 0.01 to $10 \mathrm{~s}$, Earthquake Spectra, Vol. 24, no. 1, pp. 139-171.
3. Gitterman Y., Zaslavsky, Y. and Shapira, A. (1993). “Analysis of Strong Motion Records in Israel", Proceedings of the 17th Regional European Seminar on Earthquake Engineering, Haifa, Israel, pp. 109-118.

4. Kramer, S. L. (1996). "Geotechnical Earthquake Engineering", 2nd edition, Prentice Hill, New Jersey.

5. Kun-Sung, L. and Yi-Ben, T. (2005). "Attenuation Relationships of Peak Ground Acceleration and Velocity for Crustal Earthquakes in Taiwan", Bulletin of the Seismological Society of America, Vol. 95, No. 3, pp. 1045-1058.

6. Raghukanth, S. and Iyengar, R. (2007). "Estimation of Seismic Spectral Acceleration in Peninsula India", Journal of Earth System Sciences, Vol. 116, no. 3, pp. 199-214.

7. Reiter, L. (1990). Earthquake Hazard Analysis, Colombia University Press, New York.

8. Seneviratne, H. N., Perera, L. R. K., Wijesundara, K. K., Dananjaya, R. M. S. and Jayawardena U. de S. (2019). "Seismicity around Sri Lanka from Historical Records and its Engineering Implications", Journal of IESL, (under review).

9. Thaldena, S., Perera, L. R. K. and Prame, W. (2013). "Present Status of Seismic Monitoring and Risk Assessment in and around Sri Lanka", Proceedings of the $4^{\text {th }}$ International Conference on Structural Engineering and Construction Management. Kandy, Sri Lanka. 